sents the only chance to improve survival and quality of life in these rare cases.

\section{References}

1. Enzinger FM, Weiss SW. Liposarcoma. In: Enzinger FM, Weiss SW, editors. Soft tissue tumors, 3rd ed. St Louis: Mosby; 1995. p. 431-66.

2. Attal H, Jensen J, Reyes CV. Myxoid liposarcoma of the anterior mediastinum. Diagnosis by fine needle aspiration biopsy. Acta Cytol. 1995;39:511-13.

3. Ng C, Stebbing J, Judson I. Cardiac metastasis from a myxoid liposarcoma. Clin Oncol (R Coll Radiol). 2001;13:384-5.

4. Wong SP, Ng CS, Wan S, Lee TW, Wan IY, Yim AP, et al. Giant metastatic myxoid liposarcoma causing cardiac tamponade: a case report. Jpn J Clin Oncol. 2002;32:480-2.

5. Kendall SW, Williams EA, Hunt JB, Petch MC, Wells FC, Milstein BB. Recurrent primary liposarcoma of the pericardium: management by repeated resections. Ann Thorac Surg. 1993;56:560-2.

\title{
Mechanical aortic valve malfunction: An intraoperative BioGlue complication
}

\author{
Mohsen Karimi, MD, ${ }^{a}$ Richard E. Kerber, MD, ${ }^{\mathrm{b}}$ and Jeffrey E. Everett, MD, ${ }^{a}$ lowa City, lowa
}

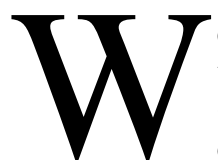

e report a case of intraoperative mechanical aortic valve malfunction after application of BioGlue (Cryolife, Inc, Kennesaw, Ga) over the aortotomy closure.

\section{Clinical Summary}

A 62-year-old woman, weighing $48 \mathrm{~kg}$, with symptomatic combined aortic stenosis and insufficiency presented for elective valve replacement.

After median sternotomy, the aorta was cannulated, and a single dual-stage venous cannula was placed through the right atrial appendage. Antegrade and retrograde cold blood cardioplegia with moderate core hypothermia $\left(32^{\circ} \mathrm{C}\right)$ constituted the cardioprotective strategy. The left ventricle was vented through the right superior pulmonary vein. Exposure of the aortic valve was obtained through a transverse aortotomy. The valve was severely calcified. The valve was excised in its entirety and calcium debrided. The patient's native root was small, and the annulus size was $19 \mathrm{~mm}$. A 19-mm St Jude Regent Mechanical valve (St Jude Medical, Inc, St Paul, Minn) was chosen because it would provide acceptable hemodynamics. The valve was seated into position successfully, and each of the leaflets moved freely. The aortotomy was next closed in 2 layers with 4-0 Prolene suture (Ethicon, Inc, Somerville, NJ). The suture line was checked for integrity with administration of cardioplegia in antegrade fashion. The closure appeared hemostatic with the

\footnotetext{
From the Division of Cardiothoracic Surgery ${ }^{\mathrm{a}}$ and Division of Cardiology, ${ }^{\mathrm{b}}$ University of Iowa College of Medicine, Iowa City, Iowa.

Received for publication Oct 19, 2004; accepted for publication Nov 4, 2004.

Address for reprints: Jeffrey E. Everett, MD, Division of Cardiothoracic Surgery, The University of Iowa Hospitals and Clinics, Iowa City, IA 52242 (E-mail: jeffrey-everett@uiowa.edu).

J Thorac Cardiovasc Surg 2005;129:1442-3

$0022-5223 / \$ 30.00$

Copyright (C) 2005 by The American Association for Thoracic Surgery doi:10.1016/j.jtcvs.2004.11.057
}

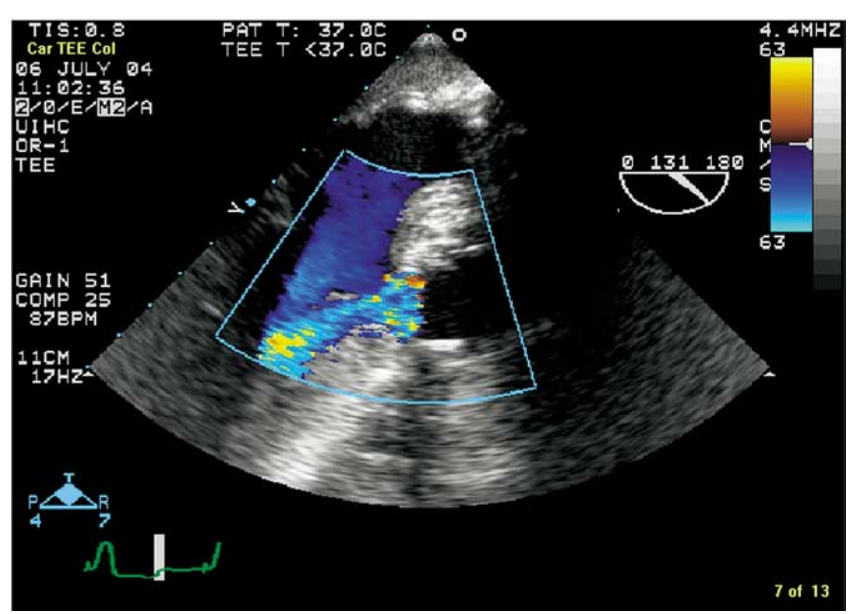

Figure 1. Aortic insufficiency after BioGlue (Cryolife, Inc, Kennesaw, Ga) application.

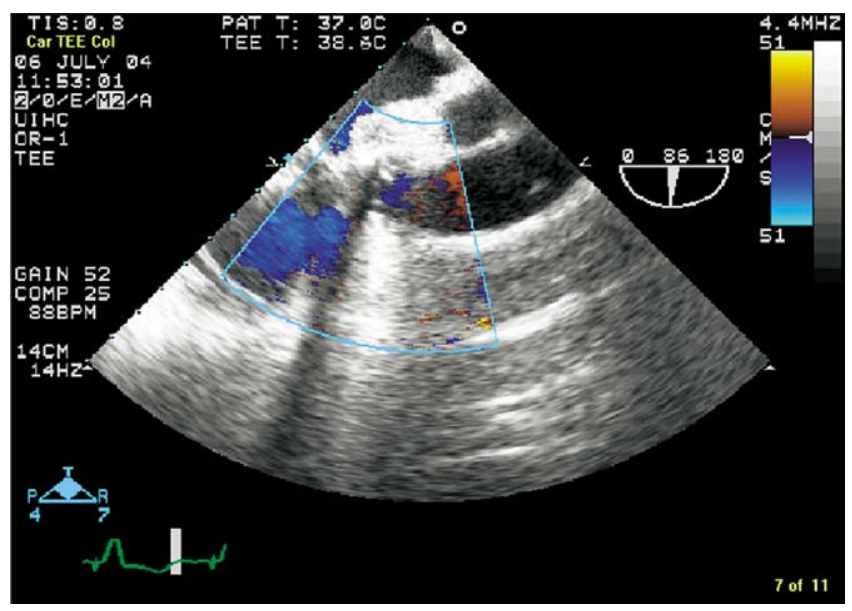

Figure 2. Restoration of valve function after removal of BioGlue. 
exception of bleeding through the suture holes. Therefore, the suture line was reinforced with BioGlue. After the patient was separated from cardiopulmonary bypass, the function of the valve was determined through intraoperative transesophageal echocardiography. There appeared to be a significant amount of aortic insufficiency (Figure 1). The crossclamp was reapplied, additional cardioplegia was given, and the suture lines were taken down. Inspection of the valve revealed that BioGlue had migrated through the suture line and impinged on 1 of the 2 leaflets. We were able to remove the glue, free the leaflet, and restore the functional hinge mechanism. The aortotomy was subsequently closed in 2 layers with 4-0 Prolene and no BioGlue reinforcement. The patient was separated from cardiopulmonary bypass with a functional valve confirmed by intraoperative transesophageal echocardiography (Figure 2).

\section{Discussion}

BioGlue is a preparation of bovine albumin cross-linked with glutaraldehyde to form a strong adhesive bond. It is supplied in a 2-barrel applicator containing albumin in 1 barrel and glutaraldehyde in 1 barrel, which are mixed at the time of application. After mixture, the glue solidifies in approximately 30 seconds and achieves maximum strength in approximately 2 to 3 minutes. ${ }^{1}$ The use of BioGlue in aortic surgery was met with great enthusiasm, because it not only increased the strength of the friable aortic walls in aortic dissection when it was applied between the dissected aortic layers but also proved effective as a sealing agent at the anastomotic suture line. ${ }^{2}$

Some experimental and clinical studies have reported the effect of BioGlue in creating local tissue damage and local inflammatory response, and increasing risk of pseudoaneurysm formation and great vessel stenosis especially in the pediatric population. ${ }^{3}$ Experimental studies in piglets have shown vascular growth impair- ment and anastomotic stricture as the result of circumferential application of BioGlue around aortic anastomosis. ${ }^{4}$ Recently, there was a case report of superior vena cava stenosis as the result of an inappropriately large amount of BioGlue placed between the roof of the left atrium, the superior vena cava, and the aortic root for persistent bleeding. ${ }^{5}$ In our case, the liquid glue seeped through the 2-layer aortotomy closure and fused the mechanical valve leaflet as a result of delayed solidification.

We believe that BioGlue is a useful adjunct in achieving a hemostatic aortic anastomosis and reapproximating the dissected aortic wall layers. However, it should be sparingly and cautiously used during mechanical valve surgery with the fear of leakage of some unsolidified glue into the valve apparatus and associated malfunctioning of the leaflets.

\section{References}

1. Spotnitz W, Burks S. Use of tissue sealants in cardiac surgery. In: Franco K, Verrier E, editors. Advanced therapy in cardiac surgery. Hamilton, Ontario: BC Decker; 2003. p. 9-10.

2. Coselli JS, Bavaria JE, Fehrenbacher J, Stowe CL, Macheers SK, Gundry SR. Prospective randomized study of a protein-based tissue adhesive used as a hemostatic and structural adjunct in cardiac and vascular anastomotic repair procedures. J Am Coll Surg. 2003;197:243-52.

3. Kazui T, Washiyama N, Bashar AH, Terada H, Suzuki K, Yamashita K, et al. Role of biologic glue repair of proximal aortic dissection in the development of early and midterm redissection of the aortic root. Ann Thorac Surg. 2001;72:509-14.

4. LeMaire SA, Schmittling ZC, Coselli JS, Undar A, Deady BA, Clubb FJ, et al. BioGlue surgical adhesive impairs aortic growth and causes anastomotic strictures. Ann Thorac Surg. 2002;73:1500-6.

5. Economopoulos GC, Dimitrakakis GK, Brountzos E, Kelekis DA. Superior vena cava stenosis: a delayed BioGlue complication. $J$ Thorac Cardiovasc Surg. 127;6:1819-21. 